\title{
Comparison of stress state around the Atera fault, central Japan, estimated using boring core samples and by improved hydraulic fracture tests
}

\author{
Yasuo Yabe ${ }^{1}$, Kiyohiko Yamamoto ${ }^{1}$, Namiko Sato ${ }^{2}$, and Kentaro Omura ${ }^{3}$ \\ ${ }^{1}$ Research Center for Prediction of Earthquakes and Volcanic Eruptions, Graduate School of Science, \\ Tohoku University, Sendai 980-8578, Japan \\ ${ }^{2}$ Advanced Industrial Science and Technology, Tsukuba Central 1, Tsukuba, Ibaraki 305-8561, Japan \\ ${ }^{3}$ National Research Institute for Earth Science and Disaster Prevention, 3-1, Tennodai, Tsukuba, Ibaraki 305-0006, Japan
}

(Received July 3, 2009; Revised November 18, 2009; Accepted December 9, 2009; Online published March 4, 2010)

\begin{abstract}
An often disputed subject is whether the stress memory of rocks can be reproduced by deformation rate analysis (DRA). Doubt has also been expressed on whether a rock can memorize its stress history. We compared the stress state around the Atera fault system, central Japan, using the hydraulic fracture test (HFT) and DRA at the same boreholes. The quality of the HFT results at these holes, especially that of the magnitude of maximum horizontal compression $\left(S_{H \max }\right)$, was recently improved by considering the tensile strength of the borehole wall. The $S_{H \max }$ azimuth determined by the DRA was about N-S. Although this is inconsistent with the geological presumption, it agrees well with the $S_{H \max }$ azimuth estimated by the HFT and the drilling-induced tensile fracture (DITF). The magnitudes of horizontal principal stresses obtained by DRA were generally consistent with the improved HFT results, and the consistency between stress states estimated by the DRA and the HFT indicates the existence of stress memory. Based on our results, we conclude that the DRA can be one option for measuring the stress state of the earth's crust.
\end{abstract}

Key words: Stress state, Atera fault system, stress memory of rocks, hydraulic fracture test, deformation rate analysis.

\section{Introduction}

Investigations on the stress state in the earth's crust provide important information on its deformation process because such information obtained from the stress state is independent of that from the strain or the strain rate determined by geodetic and/or geological methods. A variety of methods have been proposed to measure the stress state at a depth using a borehole. These include the stress relief method and the hydraulic fracture test (HFT) that are sometimes regarded as standard methods even though they are associated with a number of specific defects. For example, it is difficult to apply the stress relief method to a large depth because this method requires precisely co-axial drilling of the hole as well as knowledge of the elastic property of rocks under the in situ stress condition. For the HFT, Ito et al. (1999) pointed out that the re-opening pressure which is used to estimate the maximum horizontal compression $\left(S_{H \max }\right)$ cannot be read correctly by the ordinal HFT using a hydraulic system with large compliance.

The stress measurement techniques using core samples recovered from boreholes are yet another option to estimate the in situ stress state at a depth. These techniques are called core methods and are based on the principle of the stress memory of rocks, which is the ability of rocks to

Copyright (c) The Society of Geomagnetism and Earth, Planetary and Space Sciences (SGEPSS); The Seismological Society of Japan; The Volcanological Society of Japan; The Geodetic Society of Japan; The Japanese Society for Planetary Sciences; TERRAPUB.

doi:10.5047/eps.2009.12.002 accumulate, retain and, under certain conditions, reproduce information on the stress history (Lavrov, 2003). A typical representation of the stress memory is the Kisser effect, which can be described as follows: when a cyclic loading is applied to a rock and the maximum stress in the succeeding loading cycle is larger than that in the preceding loading cycle, the acoustic emission activity in the succeeding loading cycle is very low or not observed until the applied stress reaches the maximum stress in the preceding loading cycle. Kanagawa et al. (1977) proposed the AE method, which is an application of the Kisser effect, and Yamamoto et al. (1990) developed the deformation rate analysis (DRA), the details of which will be described later in this article. All of these methods have the principle advantage that the crustal stress can be estimated with relatively less expense and time. Further, the full-component stress tensor can be estimated using a single borehole, while only stresses in a plane normal to the borehole axis can be measured by the HFT. Stress measurement at a large depth is also difficult with the HFT and the stress relief method, although the core methods are applicable so long as core samples are recovered.

The mechanism of stress memory of rocks has been discussed by Holcomb (1993) and Yamamoto (2009). In practical terms, Villaescusa et al. (2002) demonstrated that the stress states estimated by the DRA under various geological environments were in good agreement with those obtained by the stress relief method. However, despite these efforts, the reliability of the core methods are still in dispute (e.g., 
Table 1. List of sites.

\begin{tabular}{lcccc}
\hline Site & Depth, $\mathrm{m}$ & Distance from the Atera fault & Time interval*, year & Rock type \\
\hline UEN & 340 & $1.5 \mathrm{~km}$ to SW & 4 & granite \\
& 399 & & 4 & granite \\
FKO & 296 & $4.0 \mathrm{~km}$ to SW & 4 & granodiorite \\
& 379 & & 4 & granodiorite \\
HTJ & 400 & $6.7 \mathrm{~km}$ to SW & 3 & granodiorite \\
HGW & 392 & $0.5 \mathrm{~km}$ to E & 4 & granodiorite \\
\hline
\end{tabular}

*: Time interval between sample recovering and stress measurement.

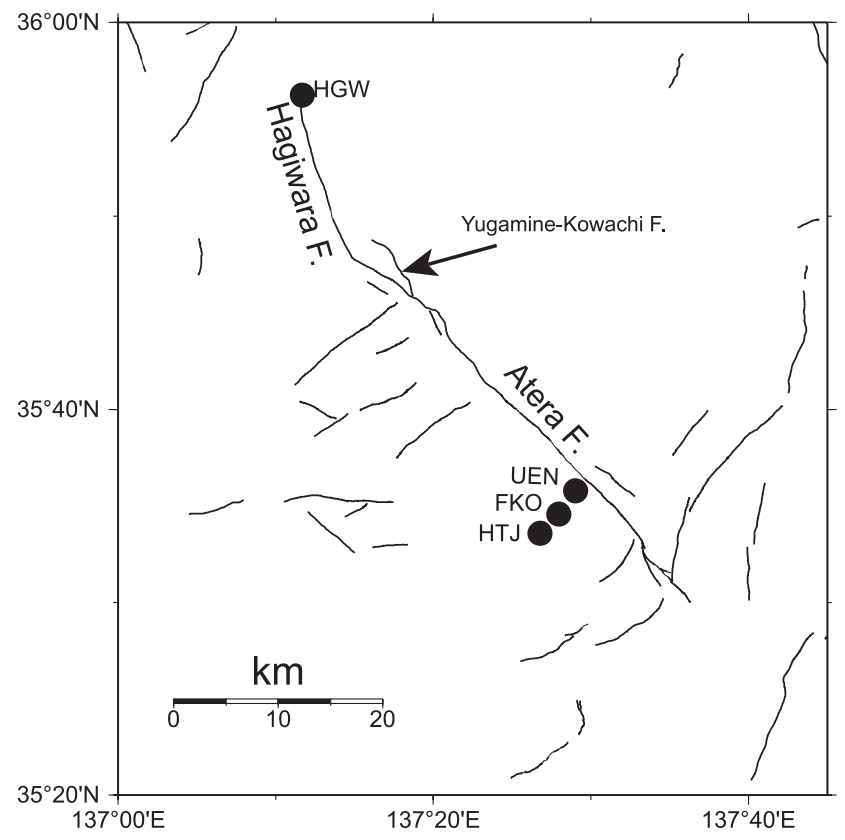

Fig. 1. Map around the Atera fault system. Solid lines indicate active fault traces.

Ljunggren et al., 2003).

The Atera fault system is located in central Japan. It extends $60-70 \mathrm{~km}$ along the strike in an approximately NWSE direction, as shown in Fig. 1. The bending of rivers and the accumulated displacement observed in the terrace of the Kiso River imply that the predominant slip of the fault system is the left-lateral strike-slip (Sugimura and Matsuda, 1965; Tsukuda et al., 1993). The slip rate is estimated to be about $2.8 \mathrm{~mm} /$ year based on the accumulated dislocation (Tsukuda et al., 1993). Toda and Inoue (1995) and Toda et al. (1996) conducted a trenching survey to investigate the paleoseismicity of the Atera fault system. Based on their results, they suggested that the latest activity on the Atera fault system is the 1586 Tensho earthquake $(M 7.8)$ and estimated the recurrence interval to be about 1800 years. The present seismicity of small earthquakes around the Atera fault system is very low, in particular along the southern part of the fault system.

The National Research Institute for Earth Science and Disaster Prevention (NIED) drilled holes at UEN, FKO, HTJ, and HGW (Fig. 1, Table 1) to determine the stress state around the Atera fault system. The UEN, FKO, and HTJ boreholes are aligned perpendicular to the strike of the Atera fault, a southern segment of the Atera fault system, on
SW side of the fault. The distance from the fault to UEN, FKO, and HTJ is about $1.5,4$, and $6.7 \mathrm{~km}$, respectively. The HGW borehole is located about $350 \mathrm{~m}$ east of the Hagiwara fault, a northern segment of the Atera fault system. Ikeda et al. (2002) carried out the HFT at these sites. However, because they used an ordinal hydraulic system with large compliance, it is possible that the re-opening pressure was not measured correctly. Yamashita et al. (2009) performed the tensile fracturing test in the laboratory using rock samples retrieved from the holes where the HFT was carried out. They re-evaluated the stress magnitude by calibrating the measurements made by Ikeda et al. (2002) to improve quality of stress estimation.

In this paper, we estimate the state of stress around the Atera fault system by applying the DRA to boring core samples recovered from boreholes in which the HFT was performed. Because the HFT is sometimes regarded as a standard technique to measure the crustal stress at a depth, we compare the stress state obtained by the DRA with that obtained by the HFT in order to assess the reliability of the DRA. The main purpose of this paper is to show that the DRA as well as the HFT can be used as standard stress measurement techniques.

\section{Method}

\subsection{Outline of the techniques}

Deformation rate analysis is a technique used to reproduce the stress memory of rocks from their non-linear relationship between applied stress and strain under a cyclic uniaxial loading (Yamamoto et al., 1990, 1993; Yamamoto, 2009). Yamamoto (2009) assumed as a principle of the DRA that the nonuniformity in stress distribution in a rock is minimized at a site. He theoretically showed that the magnitude of the in situ stress can be reproduced from the inelastic behavior of rocks using the uniaxial compression test.

\subsection{Preparation of specimens}

We estimated the stress state of six crystalline rock samples recovered from depths $(300-400 \mathrm{~m})$ at four sites (Table 1). The temperature in the boreholes was less than $30^{\circ} \mathrm{C}$ and, therefore, the effects of thermal stress on the measurements due to differences in temperature at the site and in the laboratory should be minor. The stress measurement by the DRA was performed within 4 years of the samples being recovered from depths.

Rock specimens $\left(15 \times 15 \times 35 \mathrm{~mm}^{3}\right)$ were cut from the cores $63.5 \mathrm{~mm}$ in diameter (Fig. 2) in order to reconstruct the axial stress parallel to their long axis. A strain gauge 


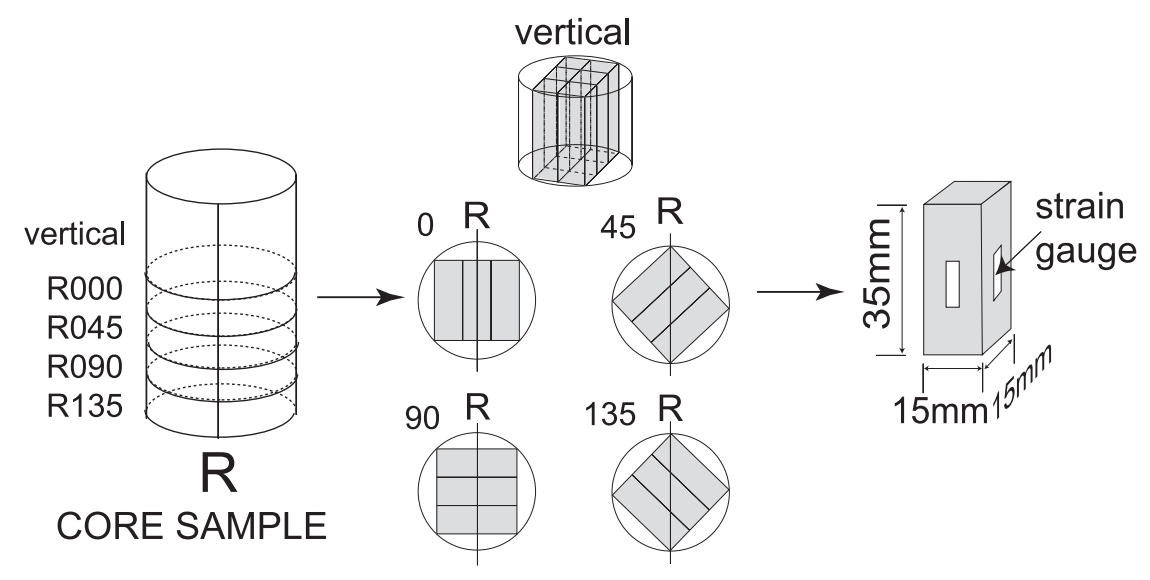

Fig. 2. Schematic illustration of sample preparation. A set of specimens is cut from a core sample. $R$ indicates the reference azimuth of the core sample.

was pasted on each free surface of each specimen. The strains measured by the individual gauges were averaged by an analog circuit to reduce the strain associated with bending effects due to eccentric loading.

The horizontal stresses in four azimuths at $45^{\circ}$ intervals were estimated to determine the horizontal principal stresses, which were measured by the HFT. We also estimated the vertical stress. Three specimens in each horizontal direction and six specimens in the vertical direction were prepared. Each specimen was assigned an identification number for convenience in the form of pppddd-V-s for a vertical specimen or pppddd-aaa-s for a horizontal specimen, where $p p p, d d d, s$, and aaa indicate the site name, the sample recovering depth, the identification number of the specimen, and the azimuth, respectively. For example, the first specimen cut from a core recovered from a depth of $379 \mathrm{~m}$ at the FKO site to estimate the vertical stress was denoted FKO379-V-1.

\subsection{Reading of the stress memory}

We detected the stress memory using the strain difference function: $\Delta \varepsilon_{i j}(\sigma)=\varepsilon_{j}(\sigma)-\varepsilon_{i}(\sigma)$, where $\sigma$ and $\varepsilon_{k}(\sigma)$ are the applied axial stress and the axial strain for $k$-th loading, respectively, and $i<j$. Each strain difference function was given a name, which took the form of pppddd-V-s-i$j$ for vertical specimens and pppddd-aaa-s-i-j for horizontal ones. The stress memory is recognized as a discontinuous change in the gradient (bending) of this function, as schematically shown in Fig. 3. The axial stress at which the bending of function occurs is called the bending stress. In an ideal case (top function in Fig. 3), the function has only one bending stress corresponding to the memorized stress. However, since the function is sensitive to fluctuations in stress rate, it is sometimes bended twice or more by a small fluctuation in the ram stroke of the loading apparatus (second to fifth functions in Fig. 3). Because the stress rate fluctuation occurs randomly, the bending stress caused by the fluctuation should depend on the combination of loading cycles $(i$ and $j)$ used to calculate the strain difference function. The bending stresses due to the fluctuation on two specimens in the same direction also differ from each other. On the other hand, the bending stress representing the stress memory is independent of either the loading cycles or the specimens, as shown in the shaded area in Fig. 3.

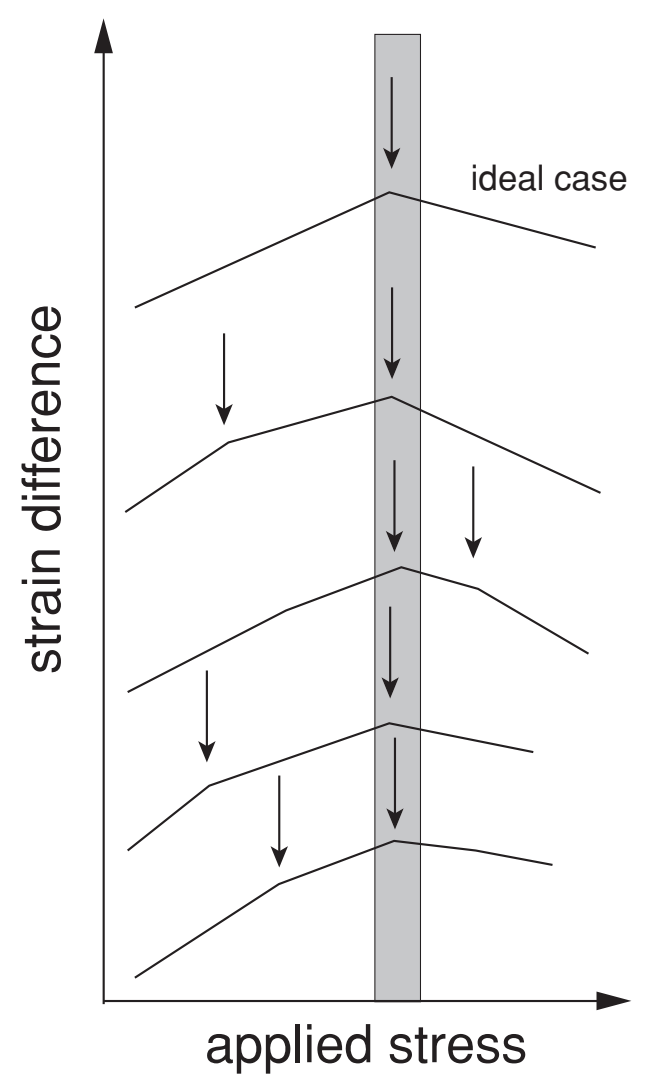

Fig. 3. Schematic illustration of the strain difference function. Arrows indicate the inelastic behavior of functions. Shaded area represents a stress magnitude range in which the inelastic behavior is commonly observed on all of the strain difference functions.

The bending of the strain difference function is sometimes unclear. One possible explanation for the unclear bending can be that the magnitude of maximum applied stress is either too large or too small. The former causes an accumulation of extra damage, which degrades the stress memory. The latter results in a short linear segment after the bending that is related to stress memory. This is associated with a difficulty in recognizing the stress memory. Therefore, at least two specimens in each direction must be tested under different magnitudes of the maximum stress.

To summarize, in this section we emphasize that we can- 
not determine the stress memory of rocks from the individual strain difference functions as described in the following section; rather, they must be surveyed in combination. We applied the following rules in determining the stress memory: (1) the bending stress representing stress memory does not depend on the maximum applied stress; (2) the bending stress representing stress memory does not depend on the combinations of loading cycles; (3) the magnitude of vertical stress does not significantly differ from the overburden pressure; (4) the dependence of axial stress on azimuth obeys a sinusoidal function; $\sigma(\theta)=\sigma_{\mathrm{m}}+\sigma_{\mathrm{d}} \cos \left(2\left(\theta-\theta_{0}\right)\right)$, where $\theta$ is the azimuth, $\theta_{0}$ is the azimuth of maximum horizontal compression, and $\sigma_{\mathrm{m}}$ and $\sigma_{\mathrm{d}}$ represent the magnitudes of isotropic and deviatoric components of horizontal stress, respectively.

\section{Results}

A typical loading history and the stress-strain relationship obtained from a specimen of FKO379-V-1 is shown in Fig. 4. The loading rate was servo-controlled to be $0.05 \mathrm{MPa} / \mathrm{s}$. Depending on the quality of the data, there could be as many as six loading cycles.

As it is expected that the stress state in the crust tends to be the lithostatic state, we assumed that the magnitudes of horizontal stress do not significantly differ from the vertical stress. Therefore, we did not perform tests with a maximum stress that was greater than threefold the vertical stress in order to restrain pollution by extra damage.

\subsection{Reading the stress memory in practice}

Here, we explain how to read the stress memory in practice by showing the strain difference functions obtained for specimens of FKO379 as typical examples.

3.1.1 Vertical stress Figure 5(a)-(e) show examples of the strain difference function for the vertical specimens recovered from a depth of $379 \mathrm{~m}$ from the FKO borehole. Because the average density of rocks measured by logging at this site was $2600 \mathrm{~kg} / \mathrm{m}^{3}$, the overburden pressure expected for this depth is $9.7 \mathrm{MPa}$. Figure 5(f)-(j) shows the significance of the bending measured by a technique proposed by Kato et al. (1991) in which two lines are fitted to the neighboring data windows before and after a target stress, and the significance of the difference between the slopes of the two lines is tested using Student's $t$ statistics. The window length before a target stress in this study is $2 \mathrm{MPa}$. Because the strain difference functions tend to be less linear after a bending, a shorter window length of 1.4 $\mathrm{MPa}$ is used for line fitting after the target stress. The target stress is shifted from point to point to obtain variations in the $t$ value with respect to the applied stress. In this plot, the $t$ value reaches a peak at a bending stress. It should be noted that the largest peak does not necessarily occur at the bending representing the stress memory-the peak in the $t$-value function simply indicates the existence of a bending. The bending representing the stress memory must be identified according to the rules stated in the preceding section.

Although large convexo-curvatures of the strain difference functions obtained for specimens of FKO379-V mask the bending of functions in some cases, we can recognize a clear bending on the function of FKO379-V-2-4-6
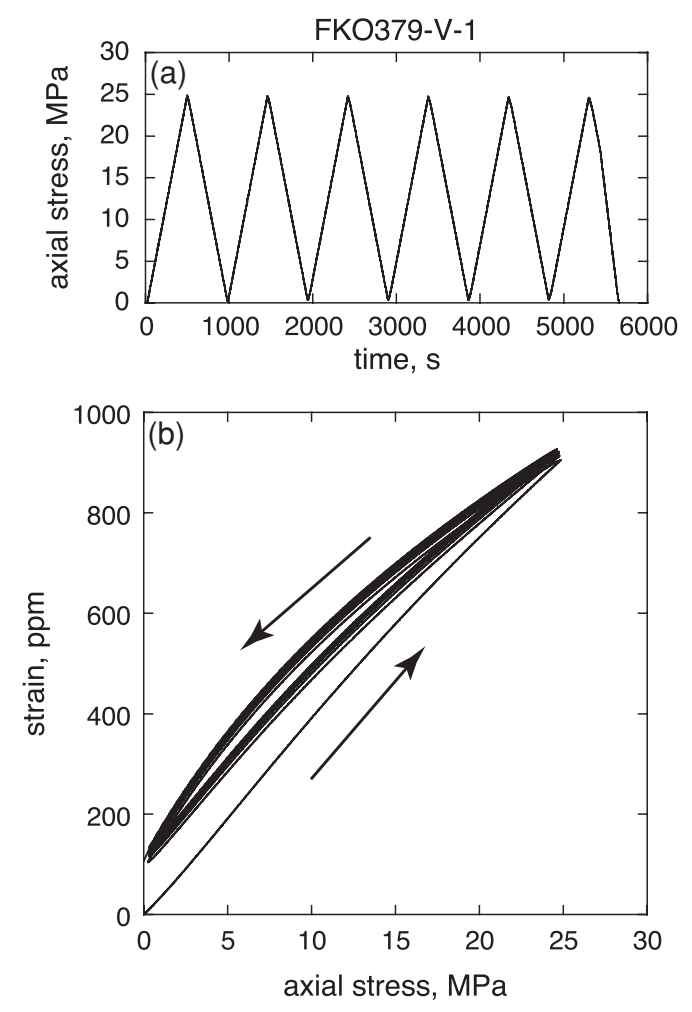

Fig. 4. Examples of (a) loading history and (b) a stress-strain curve for a vertical specimen recovered at FKO379. Arrows in (b) indicate increases in time.

(Fig. 5(b)) and FKO379-V-4-3-5 (Fig. 5(d)) at the applied axial stress of about $8 \mathrm{MPa}$, which is close to the expected overburden pressure. While the function of FKO379-V-43-5 (Fig. 5(d)) also has a bending at about $4.5 \mathrm{MPa}$, this bending stress is too small to adopt it as the vertical stress at this depth. The bending of functions of FKO379-V-13-4 (Fig. 5(a)) and FKO379-V-3-2-4 (Fig. 5(c)) at approximately $9.5 \mathrm{MPa}$ and $8.5 \mathrm{MPa}$, respectively, is not as clear as that of FKO379-V-2-4-6 and FKO379-V-4-3-5 at approximately $8 \mathrm{MPa}$, but the $t$ value reaches a peak at the corresponding axial stress. Based on a visual determination, the peak in FKO379-V-1-3-4 occurs at an axial stress slightly larger than the bending stress, primarily due to the round shape of the strain difference function. We can also find bendings on the function of FKO379-V-6-4-6 (Fig. 5(e)) at approximately $7 \mathrm{MPa}$ and $9.5 \mathrm{MPa}$. Because other functions for the vertical specimens of FKO379 have a bending between 8 and $10 \mathrm{MPa}$, the bending stress of $9.5 \mathrm{MPa}$ should be more suitable to adopt as the stress memory.

In addition to the strain difference functions in Fig. 5, we can find clear bendings at the applied stress between 8 and $10 \mathrm{MPa}$ in ten strain difference functions, including those of FKO379-V-5 (not shown here). The estimated vertical stress was $8.9 \pm 0.5 \mathrm{MPa}$.

3.1.2 Axial stress in the reference azimuth (R000) Figure 6 shows examples of strain difference functions and $t$ value functions for horizontal specimens in a reference azimuth (R000 in Fig. 2). The function of FKO379-000-1-3-4 (Fig. 6(a)) has four bendings at approximately 5, 9, 12.5, and $25 \mathrm{MPa}$, respectively. The bending at about $25 \mathrm{MPa}$ is, however, not recognized in the strain difference functions 

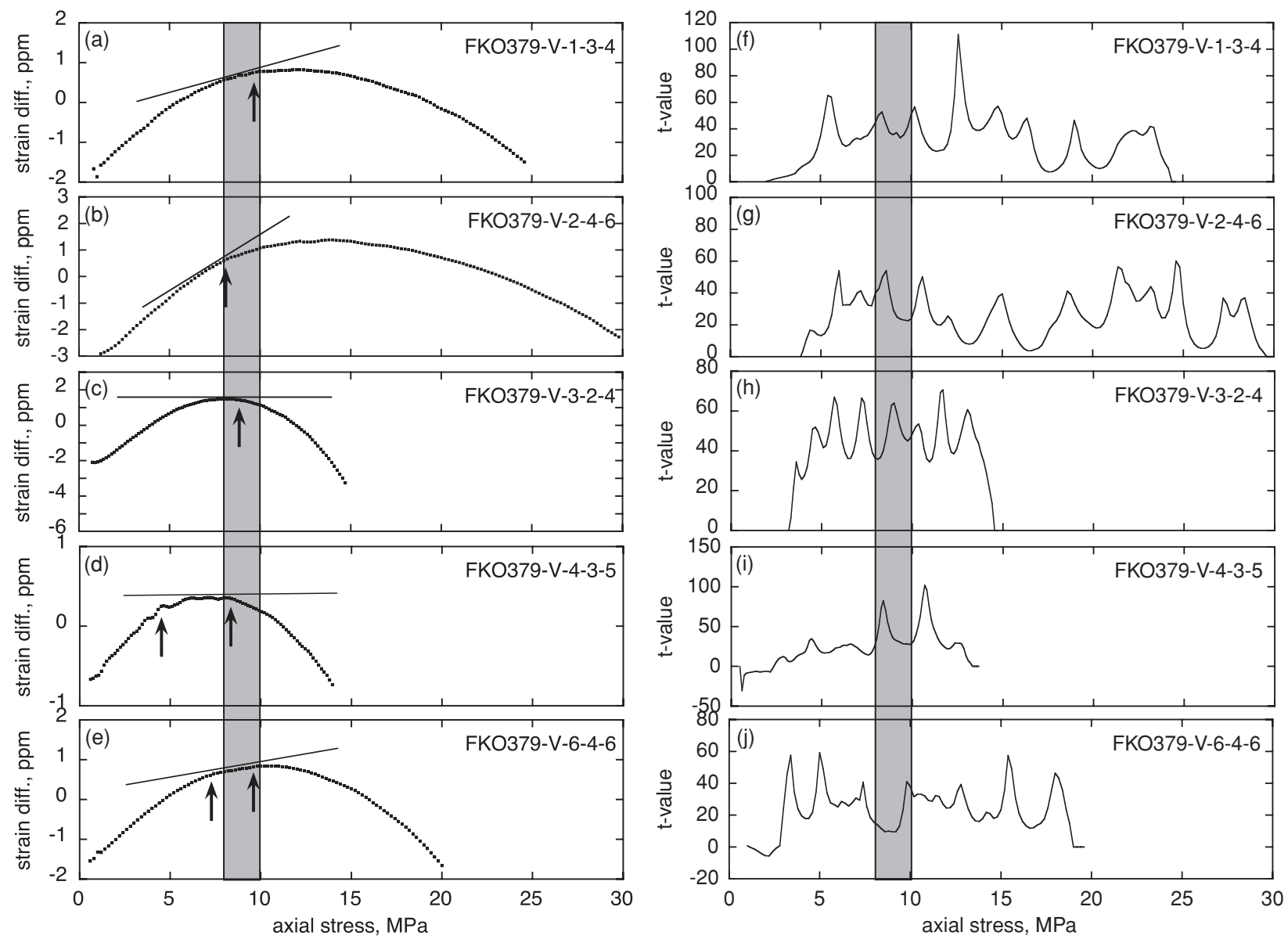

Fig. 5. (a)-(e) Examples of strain difference function for specimens recovered at FKO379. Lines attached to individual functions are drawn to emphasize changes in the gradients of functions. Arrows and shaded area are the same as in Fig. 3. (f)-(j) Examples of $t$ value as a function of applied stress. See text for details.

for different combinations of loading cycles. The function of FKO379-000-2-3-4 (Fig. 6(b)) has only one bending at approximately 12.5 MPa, while that of FKO379-000-2-4-5 (Fig. 6(c)) bends at about 6, 8.5, and 13.5 MPa. Among these three bendings, that at about $13.5 \mathrm{MPa}$ is the most significant. The bending at about $6 \mathrm{MPa}$ is followed by a concave at about 6.5 MPa. This is a typical aspect of bending due to a fluctuation of stress rate, and if this fluctuation is ignored, the gradient of function does not change at this point. Therefore, this should not be the bending related to the stress memory. The function of FKO379-000-3-35 (Fig. 6(d)) has one unclear bending at about $8 \mathrm{MPa}$ and clear bendings at about 11 and $12.5 \mathrm{MPa}$, respectively. The function of FKO379-000-3-4-5 (Fig. 6(e)) shows two clear bendings at about 10 and $12.5 \mathrm{MPa}$, respectively.

The bending stresses in the range between $12 \mathrm{MPa}$ and $14 \mathrm{MPa}$ are, therefore, the most commonly observed bendings among all of the strain difference functions for specimens of FKO379-000, while the bending stress of about $10 \mathrm{MPa}$ is also found in some functions. We therefore consider the stress of $12.8 \pm 0.3 \mathrm{MPa}$ to be the most suitable for axial stress in this azimuth. The stress of $9.8 \pm 0.8 \mathrm{MPa}$ is the second candidate.

3.1.3 Axial stress in the azimuth of R045 Figure 7 shows examples of the functions for specimens in an azimuth of $45^{\circ}$ clockwise from the reference direction (R045 in Fig. 2). The bending of function of FKO379-045-1-3-5 (Fig. 7(a)) at about $10.5 \mathrm{MPa}$ is relatively clear, but the function slightly bends at about $6.5 \mathrm{MPa}$. While the function of FKO379-045-1-4-5 (Fig. 7(b)) is contaminated by noises, probably due to fluctuations in the stress rate, it clearly bends at about $11 \mathrm{MPa}$. The function of FKO379-045-14-6 (Fig. 7(c)) has two bendings at about 10 and $15 \mathrm{MPa}$, respectively, with the former being clearer. The function of FKO379-045-2-4-5 (Fig. 7(d)) bends four times at about $6.5,9.5,11$, and $14 \mathrm{MPa}$, respectively. It should be apparent that the bending at about $14 \mathrm{MPa}$ is caused by a significant fluctuation of stress rate under an applied stress of more than $14 \mathrm{MPa}$. The left three bendings are similar in terms of clearness. The function of FKO379-045-3-3-4 (Fig. 7(e)) has two bendings at about 8 and $12 \mathrm{MPa}$, respectively.

As is shown by the shaded zone in Fig. 7, all of the functions have bendings at axial stresses between 10 and $12 \mathrm{MPa}$. We therefore estimated the magnitude of axial stress in this azimuth to be $11.6 \pm 0.6 \mathrm{MPa}$.

3.1.4 Axial stress in the azimuth of R090 Figure 8 shows examples of the functions for specimens of FKO379090, whose azimuth is $90^{\circ}$ clockwise from the reference direction (R090 in Fig. 2). The function of FKO379-0901-2-3 (Fig. 8(a)) has two bendings at about 9 and $16 \mathrm{MPa}$, respectively. However, the change in gradient at $9 \mathrm{MPa}$ is too gradual to call it a bending, while that about $16 \mathrm{MPa}$ 

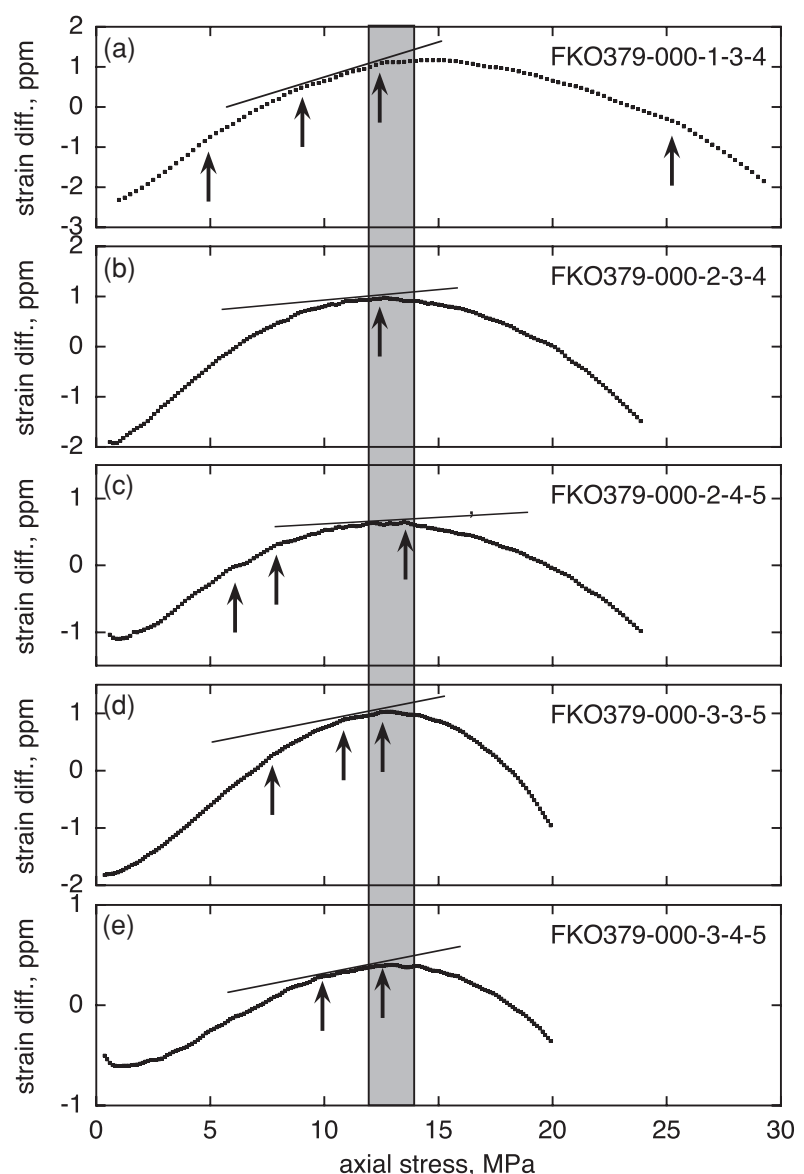

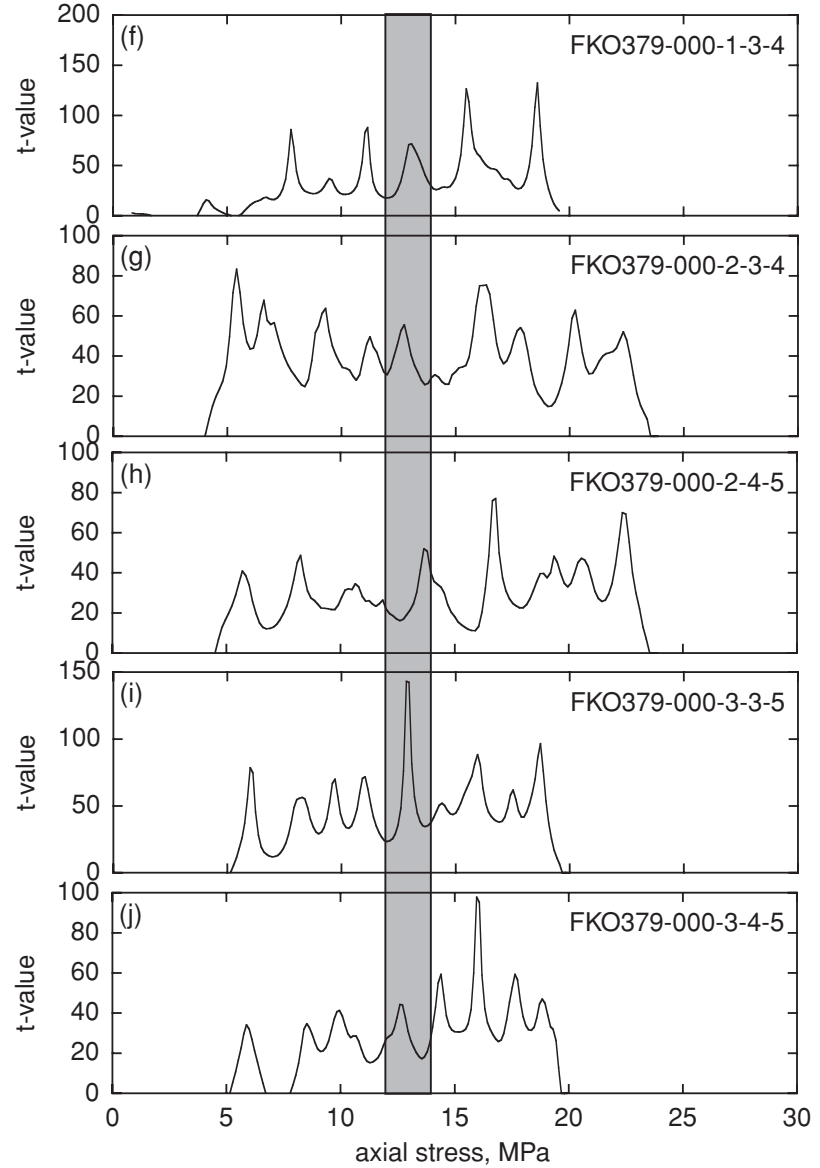

Fig. 6. Same as in Fig. 5, but for horizontal specimens parallel to the reference azimuth at FKO379. is clearly recognizable. The function of FKO379-090-12-4 (Fig. 8(b)) also has two bendings, at about 12.5 and 15.5 $\mathrm{MPa}$, respectively, although the one at $12.5 \mathrm{MPa}$ is not clear. Both bendings of the function of FKO379-090-24-5, at about 11 and $16 \mathrm{MPa}$, respectively, are significant. Although the function of FKO379-090-3-3-5 (Fig. 8(d)) has a round shape, the $t$ value suggests that the function bends at about $15 \mathrm{MPa}$. The bending stresses of the function of FKO379-090-3-4-5 (Fig. 8(e)) are about 10, 12.5, and $16 \mathrm{MPa}$, respectively.

All of the functions have bending points between 15 and $17 \mathrm{MPa}$. Therefore, the axial stress in this azimuth should be $15.5 \pm 0.3 \mathrm{MPa}$. On the other hand, because some functions commonly show bending at about $10 \mathrm{MPa}$, the stress of $10.0 \pm 0.7 \mathrm{MPa}$ is the second candidate for the axial stress in this azimuth.

3.1.5 Axial stress in azimuth of R135 Figure 9 shows examples of the functions for specimens of FKO379135 , whose azimuth is $135^{\circ}$ clockwise from the reference direction (R135 in Fig. 2). The function of FKO379-1351-3-6 (Fig. 9(a)) bends at about 13 and 15.5 MPa. The function of FKO379-135-2-3-5 (Fig. 9(b)) has two bendings at about 13 and $16 \mathrm{MPa}$, respectively, with that at about $13 \mathrm{MPa}$ being more recognizable. The gradient of function of FKO379-135-2-5-6 (Fig. 9(c)) changes at about 15 and $19 \mathrm{MPa}$, and it appears that there are a few bending (no arrows are attached) at stresses between 5 and $10 \mathrm{MPa}$. Because these latter stresses are a combination of convex and concave, they should be results of stress rate fluctuation. The function of FKO379-135-2-4-6 (Fig. 9(d)) has a bending at about $15 \mathrm{MPa}$. The gradient changes in this function at about 6 and $19 \mathrm{MPa}$, respectively, are too gradual to call them bendings. The function of FKO379-135-3-2-4 (Fig. 9(e)) has a minor bending at about 14.5 MPa.

Bending stresses between 14 and $16 \mathrm{MPa}$ are commonly observed, while clear bending at about $13 \mathrm{MPa}$ can be found in a few functions. The axial stress in this azimuth is therefore estimated to be $16.0 \pm 0.6 \mathrm{MPa}$.

3.1.6 Evaluation of azimuthal dependence of axial stresses The sinusoidal function in rule (4) is fitted to the azimuthal variation in estimated stress magnitude (Fig. 10). Note that the azimuth in Fig. 10 is not measured from the reference direction but from the geographic north. The core sample recovered from a depth of $379 \mathrm{~m}$ at the site of the FKO borehole was oriented by comparing fractures on the core with those on the borehole wall delineated by the borehole televiewer. The reference direction (R000) of this core is N53E.

The best-fit sinusoidal function for the most suitable combination (primary data set) of estimated axial stresses are shown in Fig. 10(a). The $S_{H \text { max }}$ azimuth is N172E, and the isotropic and the deviatoric stress are 14.0 $\pm 0.2 \mathrm{MPa}$ and $2.6 \pm 0.2 \mathrm{MPa}$, respectively.

The axial stress in the azimuth of R000 and R090 has a second candidate, as stated above. Figure 10(b) shows the best-fit sinusoidal functions for data sets in which the 

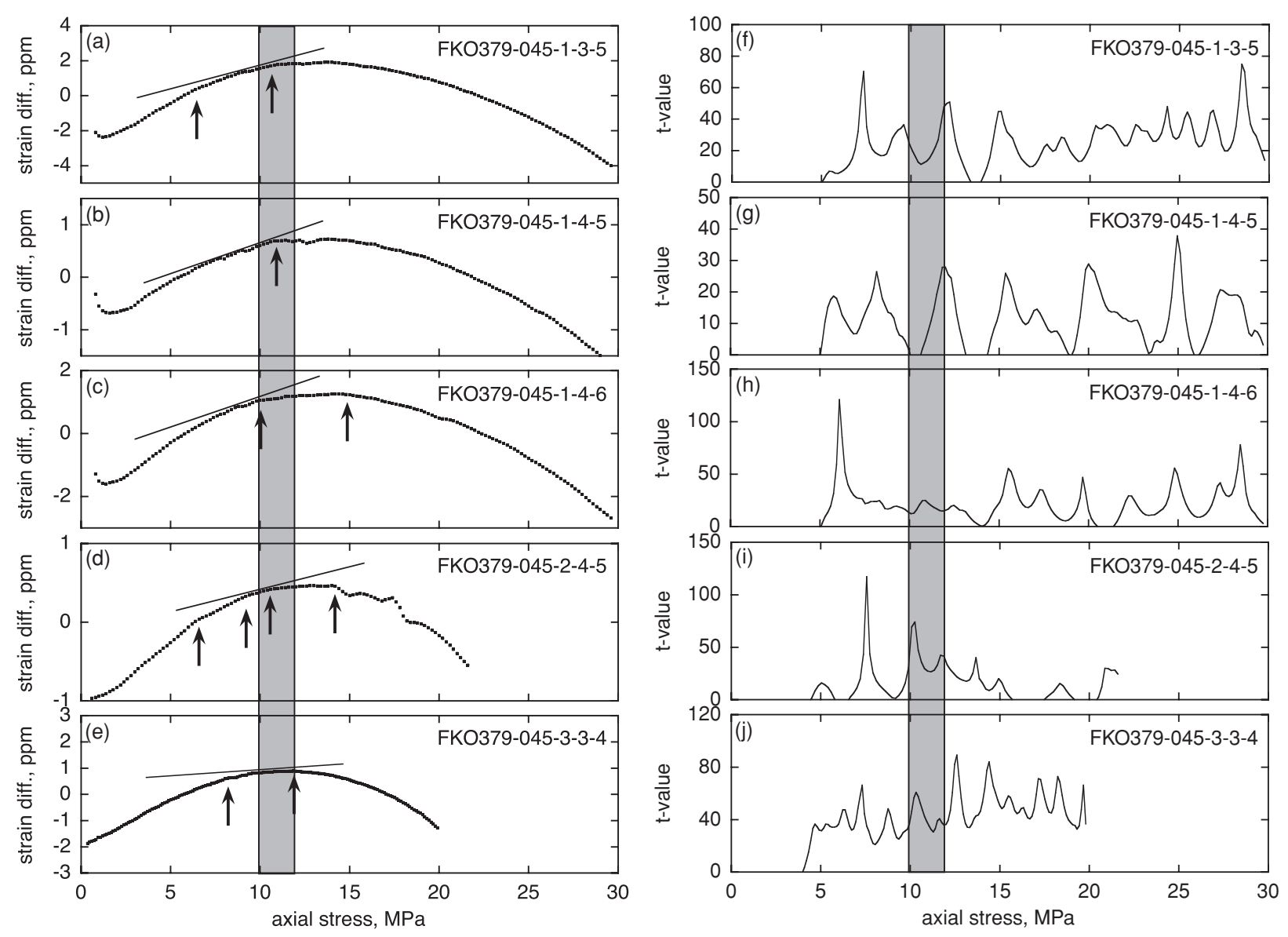

Fig. 7. Same as in Fig. 5, but for horizontal specimens at an azimuth of $45^{\circ}$ from the reference azimuth at FKO379.

second candidate of axial stress in azimuth of R000 and/or $\mathrm{R} 090$ is adopted. If the second candidate is assumed to be the axial stress in the azimuth of R090 (N143E), we cannot find a sinusoidal function satisfying the data (dashed and dot-dashed lines in Fig. 10(b)). Only for the data set with the second candidate of R000 (N53E) and the primary estimations for other azimuths, the best-fit sinusoidal function (solid line in Fig. 10(b)) can reproduce the azimuthal variation in the axial stress. In this case, the $S_{H \max }$ azimuth is N162E and the isotropic and the deviatoric stress is $13.2 \pm 0.6$ and $3.6 \pm 0.8 \mathrm{MPa}$, respectively. This is very close to the estimation for the primary data set. Further, the root mean square (rms) residual for the second best data set is $1.3 \mathrm{MPa}$, while that for the primary data set is as small as $0.12 \mathrm{MPa}$. We then adopt the stress state estimated from the primary data set as the in situ stress state at a depth of $379 \mathrm{~m}$ at the FKO borehole.

\subsection{Stress states at other sites}

The stress states at other sites are shown in Fig. 11. The estimated magnitudes of the vertical, isotropic, and deviatoric stresses are summarized in Table 2. Because we could not orient the core sample of HTJ400 (Fig. 11(d)), the azimuthal variation in magnitude of the axial stress at this site is represented relative to the arbitral reference direction. The bendings of strain difference functions for specimens of HGW392 were unclear in most cases. We therefore performed stress measurements in eight azimuths to increase the reliability of estimation (Fig. 11(e)).

\section{Discussion}

\subsection{Reliability of $S_{H_{\max }}$ azimuth}

The spatial variation in the $S_{H \max }$ azimuth is shown in Fig. 12. The $S_{H \max }$ azimuth at UEN340 is about E-W, which is consistent with the fault motion expected from the geological information. Because, however, the magnitude of the deviatoric stress at this site is not larger than the estimation error of axial stresses in the individual azimuth, the estimated $S_{H \max }$ azimuth is not expected to be reliable. The $S_{H \max }$ azimuths at other sites close to the Atera fault (UEN399, FKO296, and FKO379) are almost N-S. The $S_{H \text { max }}$ azimuth of HGW392 is about NE-SW. These results mean that a right-lateral strike-slip should occur along the Atera fault system, They are not in agreement with the geological presumption that the Atera fault system consists of left-lateral strike-slip faults.

Ikeda et al. (2002) performed the HFT at UEN, FKO, and HTJ and reported that the $S_{H \text { max }}$ azimuths estimated by the HFT were also N-S. Because the $S_{H \max }$ azimuth is measured from observations of fracture on the borehole wall, its reliability is not affected by compliance of the hydraulic system used for the HFT. Drilling-induced tensile fracture (DITF) extending in the NE-SW direction was found at HGW (Yamashita, personal communication), suggesting that the $S_{H \max }$ azimuth at this site is NE-SW. The differences between $S_{H \max }$ azimuths thus estimated by traditional techniques and by the DRA are less than $20^{\circ}$. We then consider the possibility that the contradiction between the esti- 

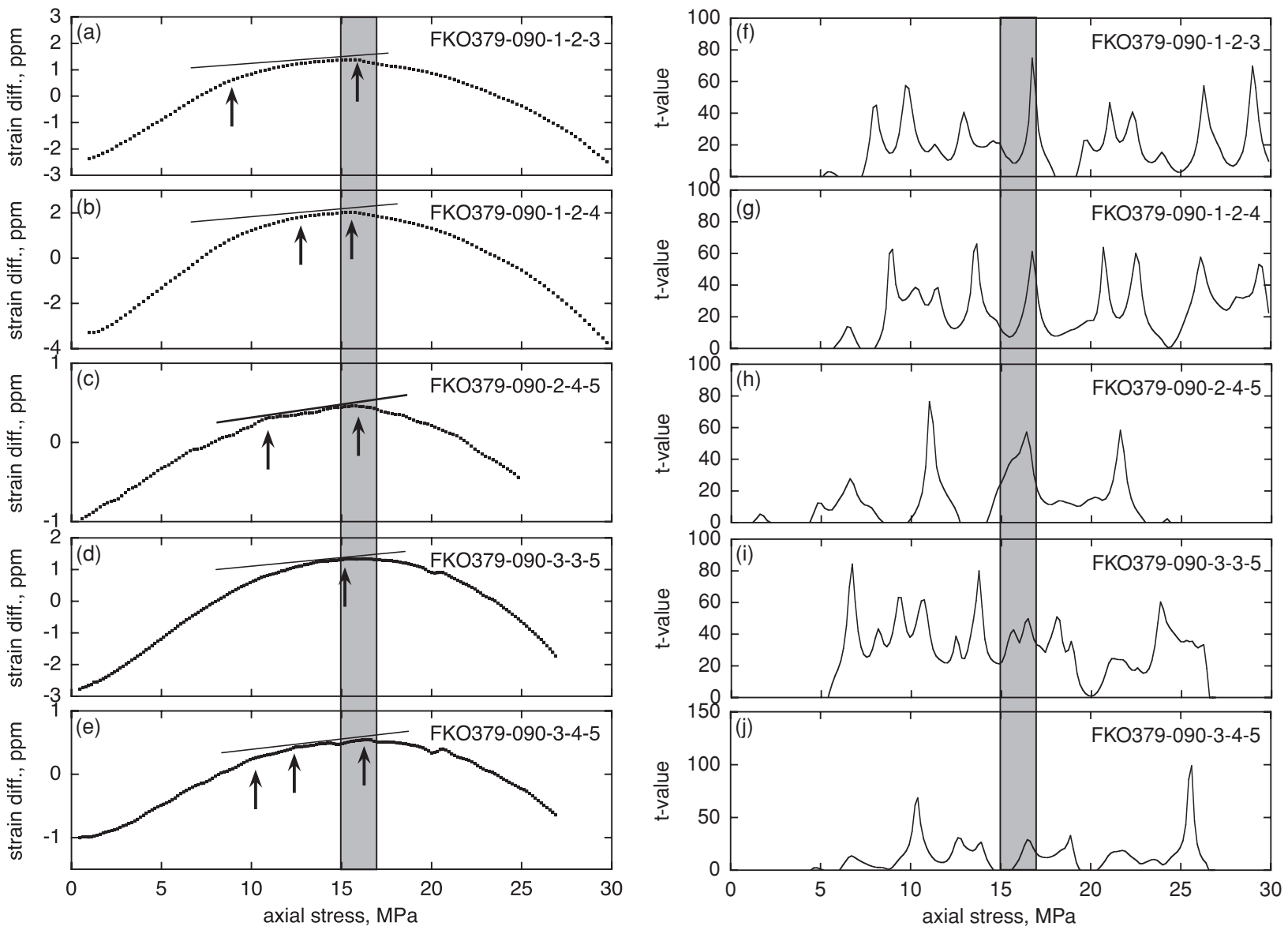

Fig. 8. Same as in Fig. 5, but for horizontal specimens at an azimuth of $90^{\circ}$ from the reference azimuth at FKO379.

mated $S_{H \max }$ azimuth and the geological presumption is not due to the unreliability of stress determination by the DRA.

Because the dip of faults in the Atera fault system is nearly vertical, fault slip induced by the present state of crustal stress should be a right-lateral strike-slip, which is in contrast to the expectation based on the geological information. A possible reason for this inconsistency is a temporal change in the stress state, as discussed by Yamashita et al. (2009). However, any further discussion on this inconsistency is beyond the scope of this study.

\subsection{Reliability of stress magnitude}

The magnitudes of $S_{H \max }$ and $S_{h \min }$ (the minimum horizontal compression) estimated by the DRA and the HFT are compared in Fig. 13. The error bars attached to the HFT results in this figure represent only errors originating from the tensile strength measurement.

4.2.1 Stress magnitude at UEN The stress magnitudes at the site of UEN were estimated by the HFT at only one depth, $347 \mathrm{~m}$, while they are determined at two depths (340 and $399 \mathrm{~m}$ ) by the DRA in this study. The magnitude of $S_{h \text { min }}$ at UEN340 estimated by the DRA is equal to that estimated by the HFT at a depth of $347 \mathrm{~m}$, while the $S_{H \max }$ determined by the respective techniques differs by $4 \mathrm{MPa}$. This difference in $S_{H \max }$ magnitude is significantly larger than the errors in the axial stress estimation by the DRA (0.5-0.7 MPa, Fig. 11(a)).

In the case of the HFT, the magnitude of $S_{H \max }$ is calculated from the following equation: $S_{H \max }=3 S_{h \min }-$
$P_{\mathrm{b}}-T-P_{\mathrm{p}}$, where $P_{\mathrm{b}}, T$, and $P_{\mathrm{p}}$ are breakdown pressure, tensile strength of the borehole wall, and pore pressure, respectively. Therefore, the error in $S_{H \max }$ estimation is threefold larger than that of $S_{h \min }$, being about $2.4 \mathrm{MPa}$ at this site. The remainder of the discrepancy may be explained by errors in the measurements of shut-in pressure, breakdown pressure, and pore pressure. However, they are not well understood at the present time.

The magnitudes of horizontal principal stresses at UEN399 determined by the DRA are 1-2 MPa smaller than those determined by the HFT. Although the error in fitting the sinusoidal function to the azimuthal dependence of axial stress in the DRA is negligibly small (Table 2), the estimation error of axial stress in each azimuth is relatively large (0.6-0.8 MPa). The estimation error in tensile strength by Yamashita et al. (2009) was $0.8 \mathrm{MPa}$ at this site. The differences between estimations by the DRA at UEN399 and the HFT at UEN347 should not be significant.

4.2.2 Stress magnitude at FKO The HFT were performed at four depths between 243 and $276 \mathrm{~m}$ at FKO. The estimated magnitudes of $S_{h \min }$ by the HFT are in a range between 8.0 and 10.0 MPa. On the other hand, the DRA was applied to cores recovered from two depths of 296 and $379 \mathrm{~m}$. The $S_{h \min }$ magnitude estimated by the DRA at FKO296 was $9.3 \mathrm{MPa}$, which is in the range of $S_{h \text { min }}$ magnitudes determined by the HFT. The $S_{h \text { min }}$ magnitude at FKO379 by the DRA is $11.4 \mathrm{MPa}$, which is slightly larger than the estimation by the HFT. The errors in sinusoidal 

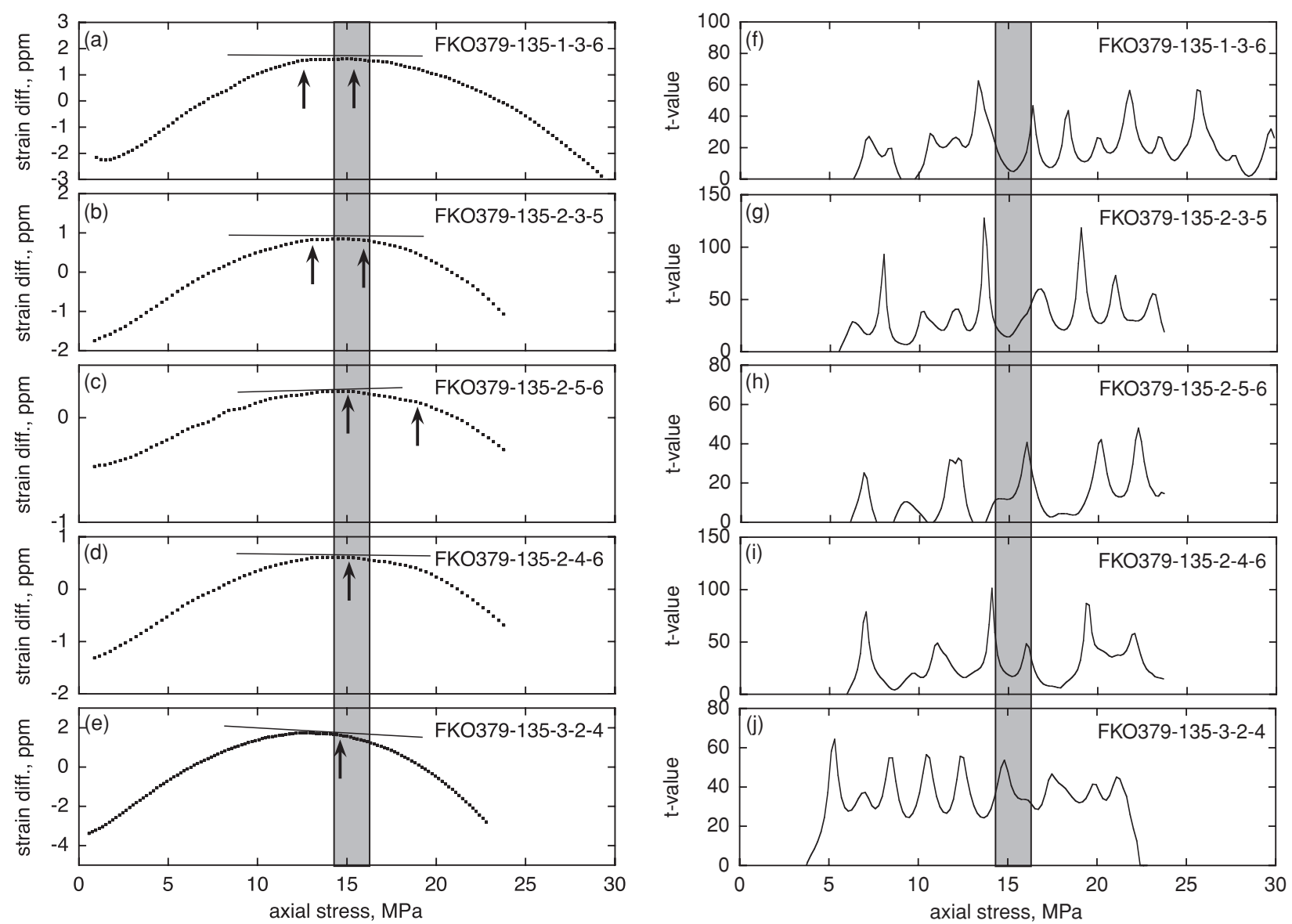

Fig. 9. Same as in Fig. 5, but for horizontal specimens at an azimuth of $135^{\circ}$ from the reference azimuth at FKO379.
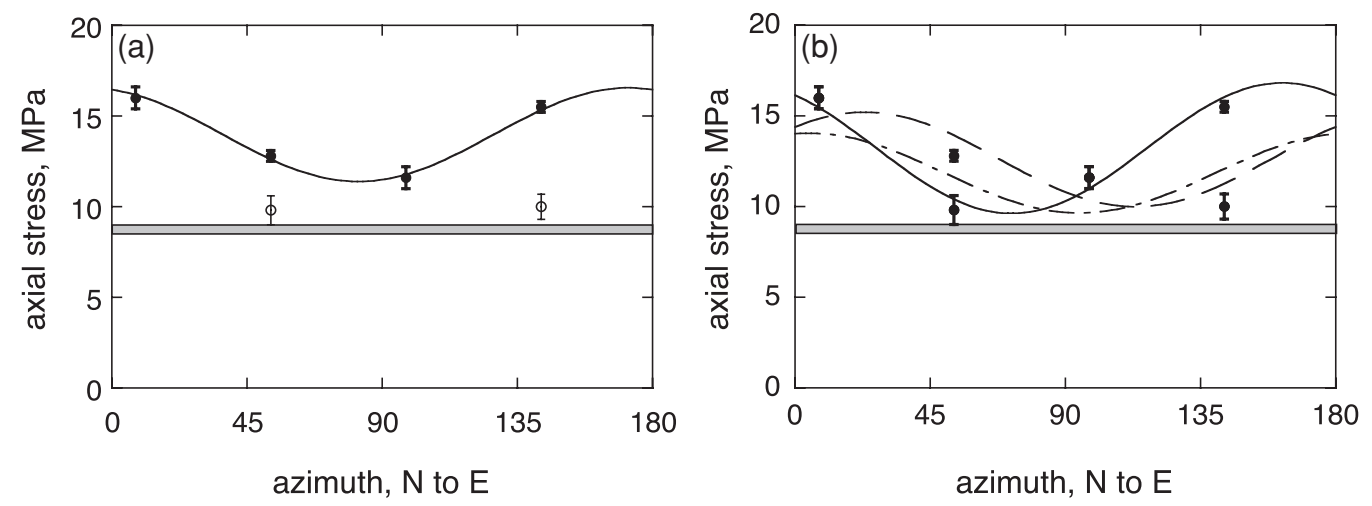

Fig. 10. Dependence of the estimated horizontal stress on azimuth at FKO379. (a) Solid and open circles indicate the primary and the secondary reading of stress memories, respectively. Shaded zone represents the range of estimated vertical stress. Solid line indicates the sinusoidal function fitted to the primary data set of stress memory reading. (b) Alternative sinusoidal functions fitted to other data sets of reading. Solid line; the secondary for R000 and the primary for R090. Dashed line; the primary for both R000 and the secondary R090. Dot-dashed line; the secondary for both R000 and R090.

function fitting, estimation of axial stresses in individual azimuth, and measurement of tensile strength are 0.4, 0.3-0.6 and 0.6-0.7 $\mathrm{MPa}$, respectively. Considering these errors, the difference between $S_{h \text { min }}$ magnitude at FKO379 and that by the HFT should be negligible.

The magnitude of $S_{H \max }$ at FKO estimated by the HFT shows a large scatter from 13.7 to $18.9 \mathrm{MPa}$; in comparison, the magnitude at FKO296 and FKO379 by the DRA is 12.7 and 16.6 MPa, respectively. The estimation at FKO379 by the DRA is within the range of the HFT estimations. Be- cause the estimation error in the fitting of sinusoidal function in the former case is as large as $1.2 \mathrm{MPa}$, it can also be said that the $S_{H \max }$ at FKO296 agrees with estimations by the HFT.

4.2.3 Stress magnitude at HTJ Since the depth of the stress measurements by the HFT and that by the DRA at HTJ differ by about $140 \mathrm{~m}$, it is not clear whether we can directly compare the results obtained by the respective techniques. The $S_{h \text { min }}$ magnitudes measured by the HFT at three depths from 249 to $266 \mathrm{~m}$ ranged from 11.8 to $14.2 \mathrm{MPa}$, 

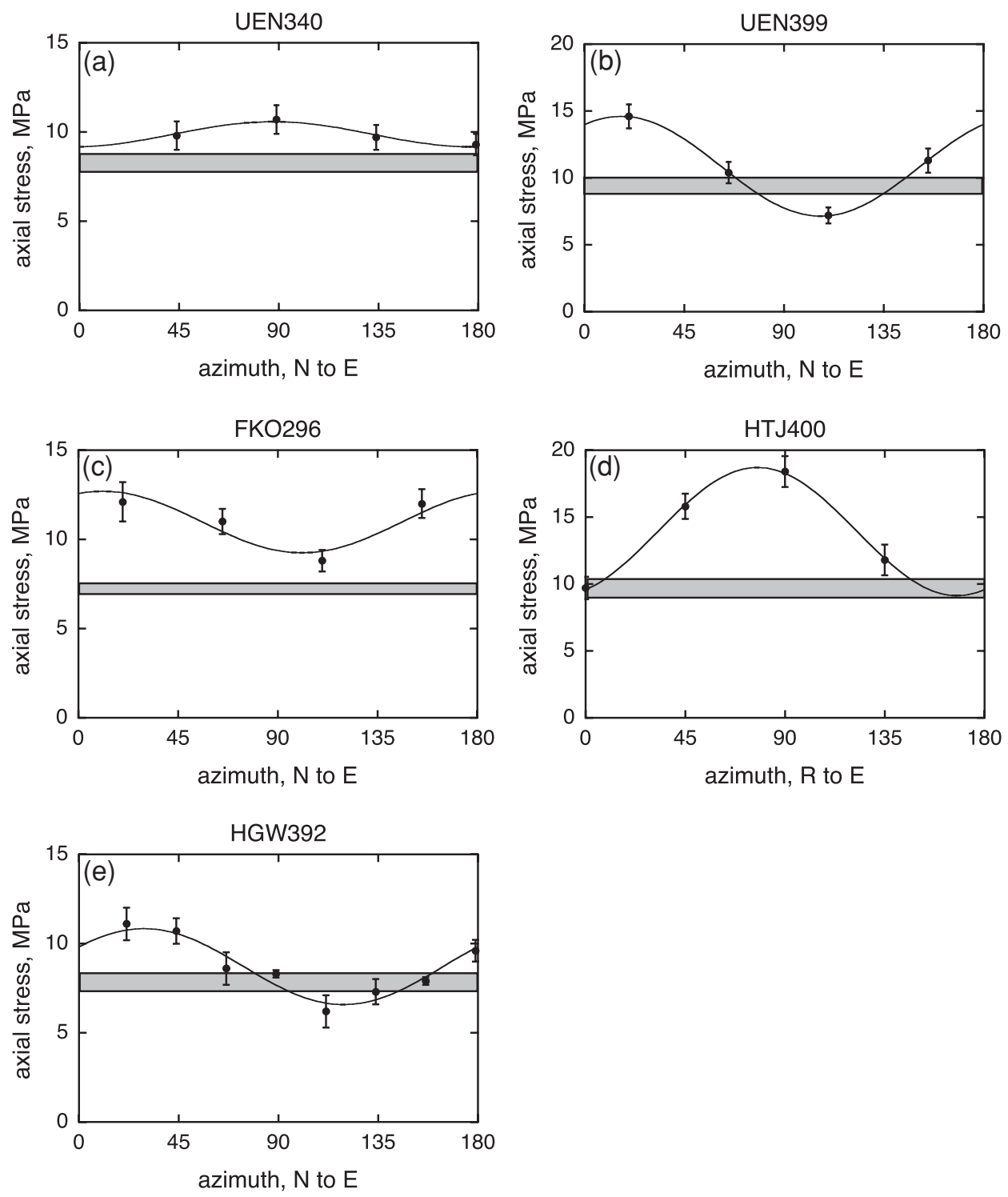

Fig. 11. Same as in Fig. 10(a), but for (a) UEN340, (b) UEN399, (c) FKO296, (d) HTJ400, and (e) HGW392.

Table 2. Summary of estimated stresses.

\begin{tabular}{|c|c|c|c|c|c|c|}
\hline Site & Depth, m & $\sigma_{\mathrm{v}}^{*}, \mathrm{MPa}$ & $\sigma_{\mathrm{m}}^{* *}, \mathrm{MPa}$ & $\sigma_{\mathrm{d}}^{* *}, \mathrm{MPa}$ & $\theta_{0}^{* *}$ & $r^{* * *}$ \\
\hline \multirow[t]{2}{*}{ UEN } & 340 & $8.4 \pm 0.5$ & $9.9 \pm 0.1$ & $0.7 \pm 0.2$ & N87E & $0.07 \pm 0.02$ \\
\hline & 399 & $9.4 \pm 0.6$ & $10.9 \pm 0.0^{\dagger}$ & $3.7 \pm 0.0^{\dagger}$ & N17E & $0.34 \pm 0.00^{\ddagger}$ \\
\hline \multirow[t]{2}{*}{ FKO } & 296 & $7.3 \pm 0.3$ & $11.0 \pm 0.5$ & $1.7 \pm 0.7$ & N11E & $0.16 \pm 0.07$ \\
\hline & 379 & $8.9 \pm 0.5$ & $14.0 \pm 0.2$ & $2.6 \pm 0.2$ & N172E & $0.19 \pm 0.02$ \\
\hline HTJ & 400 & $9.7 \pm 0.7$ & $13.9 \pm 0.1$ & $4.8 \pm 0.2$ & $\mathrm{~N} / \mathrm{A}^{\S}$ & $0.35 \pm 0.02$ \\
\hline $\mathrm{HGW}$ & 392 & $7.9 \pm 0.5$ & $8.7 \pm 0.2$ & $2.1 \pm 0.3$ & N29E & $0.24 \pm 0.04$ \\
\hline
\end{tabular}

while that at HTJ400 determined by the DRA was $9.1 \mathrm{MPa}$. The errors in fitting of the sinusoidal function, estimation of individual axial stress, and measurement of tensile strength are $0.3,0.7-1.0$, and $0.6 \mathrm{MPa}$, respectively. Therefore, we can conclude that the $S_{h \min }$ magnitudes obtained by the respective techniques of the DRA and the HFT agree with each other.

The $S_{H \max }$ magnitudes by the HFT were close to threefold greater than the vertical stress, while that by the DRA was about twice the vertical stress. The difference between the $S_{H \max }$ magnitudes by the respective techniques is more than $7 \mathrm{MPa}$. This difference cannot be explained by estimation errors.

As stated above, the depths of the stress measurement by the two techniques are separated by about $140 \mathrm{~m}$. It is then possible that the difference between estimations is a result of depth variation in stress magnitude. Alternatively, it is also possible that this difference is caused by a defect 


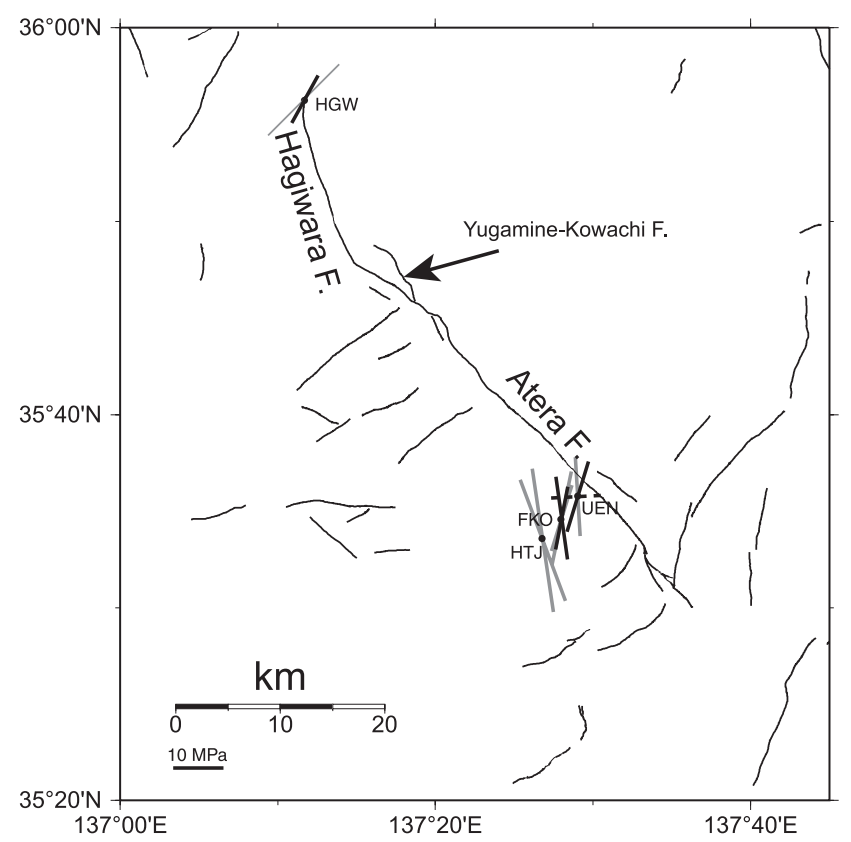

Fig. 12. The $S_{H \max }$ azimuths around the Atera fault system. Black and gray lines indicate the $S_{H \max }$ azimuth determined by the DRA and the HFT, respectively. The $S_{H \max }$ azimuth at HGW was obtained from DITF. Because the $S_{H \max }$ estimation at UEN340 was less reliable (see text), it is shown by dashed line. Except for the gray line at HGW, the length of line is proportional to the $S_{H \max }$ magnitude.

of either or both of the techniques. A potential problem in the DRA is the restriction of maximum applied stress. Because we applied the maximum stress at less than threefold greater than the expected vertical stress, we were unable to determine such a large magnitude of $S_{H \max }$ as obtained by the HFT at HTJ, even if it was memorized in the rocks. If this is the case, the estimated $S_{H \max }$ by the DRA should be an artifact due to misidentification of the bending point on the strain difference functions of R045 and R090, which are close to the $S_{H \max }$ azimuth.

On the other hand, while the HFT was performed at depths of 249-266 m, Yamashita et al. (2009) estimated the tensile strength of cores recovered from a depth of about $325 \mathrm{~m}$ because they could obtain only one test piece for tensile stress measurement from cores recovered from depths of 249-266 m. Although they carefully selected cores having similar physical properties as rocks at depths of the HFT based on the logging data to estimate appropriate tensile strength of borehole wall at depths of the HFT, it is possible that the tensile strength of rocks at depths of 249-266 m significantly differs from that at a depth of $325 \mathrm{~m}$. Actually, the tensile strength of a core sample recovered from a depth of about $245 \mathrm{~m}$ was about $3 \mathrm{MPa}$ smaller than that from $325 \mathrm{~m}$ (Yamashita, personal communication), although its reliability is low. Because the tensile strength affects only the $S_{H \max }$ magnitude, the inconsistency of the $S_{H \max }$ estimation can be reduced to $4 \mathrm{MPa}$ if the tensile strength of the core from $245 \mathrm{~m}$ is assumed. This is, however, still larger than the sum of estimation errors (by about $2 \mathrm{MPa}$ ).

The errors in pressure measurements in the HFT may explain the discrepancy. However, current knowledge on the errors associated with pressure measurement in the HFT
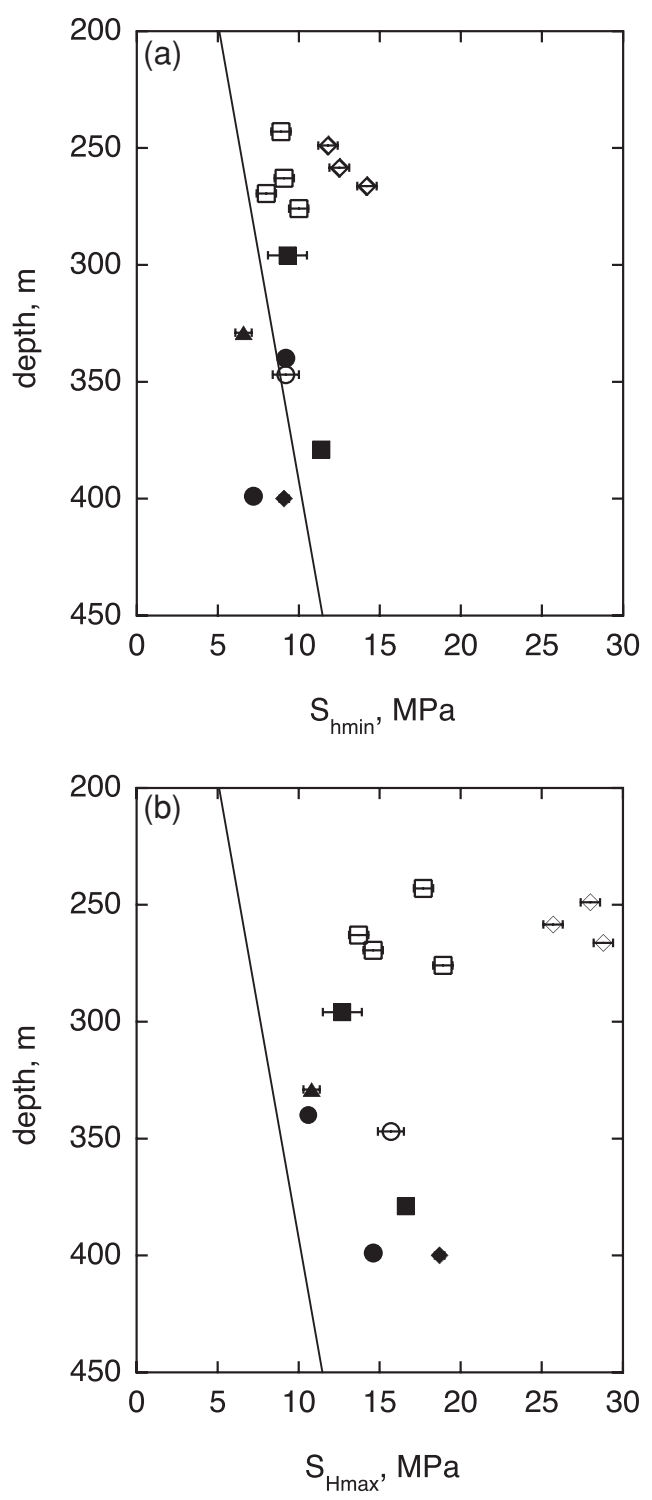

Fig. 13. Depth dependence of the magnitudes of (a) $S_{h \min }$ and (b) $S_{H \max }$. Solid line shows the overburden pressure expected for a density of $2600 \mathrm{~kg} / \mathrm{m}^{3}$. Solid and open symbols represent measurements by the DRA and the HFT, respectively. Circles, squares, diamonds, and triangles indicate measurements at UEN, FKO, HTJ, and HGW.

is limited, as stated above. Further studies on this subject are desired.

\section{Conclusions}

The crustal stress around the Atera fault system was measured by the DRA. Because the HFT is sometimes regarded as a standard technique to estimate the state of crustal stress, we compared the estimation by the DRA with that by the HFT. The $S_{H \max }$ azimuths obtained by the DRA agree well with those by the HFT and the DITF. The stress magnitudes determined by the DRA are also consistent with those by the HFT, as long as the difference in measurement depths of two methods is small. These results imply that quality of stress measurement by the DRA using core samples up to 4 years old is never worse than that by the HFT. As such, the DRA can be one option for carrying out stress measurements at less expense and time. 
Acknowledgments. Comments and information provided by Dr. F. Yamashita, NIED, were useful for improving the quality of this article. The authors thank Prof. O. Sano, Earthquake Research Institute, University of Tokyo, and Prof. A. Mukai, Nara Sangyo University, for their critical and constructive comments.

\section{References}

Holcomb, D. J., General theory of the Kaiser effect, Int. J. Rock Mech. Min. Sci. Geomech. Abstr., 30, 929-935, 1993.

Ikeda, R., K. Omura, T. Matsuda, and Y. Iio, Spatial and temporal variation of in-situ stress in and around active fault zones in central Japan, Eos Trans. AGU, 83(47), Fall Meet. Suppl., Abstract T62C-1338, 2002.

Ito, T., K. Evans, K. Kawai, and K. Hayashi, Hydraulic fracture reopening pressure and the estimation of maximum horizontal stress, Int. J. Rock Mech. Min. Sci., 36, 811-826, 1999.

Kanagawa, T., M. Hayashi, and N. Nakasa, Estimation of spatial geostress components in rock samples using the Kaiser effect of acoustic emission, Proc. Jpn. Soc. Civil Eng., 285, 63-75, 1977 (in Japanese).

Kato, N., S. Nakao, H. Yamamoto, K. Yamamoto, and T. Hirasawa, A statistical method for detecting linear trend changes and its application to Deformation Rate Analysis, Tohoku Geophys. J. (Sci. Rep. Tohoku Univ. Ser. 5), 34, 13-34, 1991.

Lavrov, A., The Kaiser effect in rocks: principles and stress estimation techniques, Int. J. Rock Mech. Mining Sci., 40, 151-171, 2003.

Ljunggren, C., Y. Chang, T. Janson, and R. Christiansson, An overview of rock stress measurement methods, Int. J. Rock Mech. Mining Sci., 40, 975-989, 2003.

Sugimura, A. and T. Matsuda, Atera fault and its displacement vectors, Geol. Soc. Am. Bull., 76, 509-522, 1965.

Toda, S. and D. Inoue, Paleoseismicity of the Atera fault system and 1586
Tensho earthquake: trenching studies at Ogo, Aonohara and Dendahara, central Japan, Zisin (J. Seismol. Soc. Jpn.), 48, 401-421, 1995 (in Japanese with English abstract).

Toda, S., D. Inoue, and K. Miyakoshi, Paleoseismicity of the Atera fault system, central Japan, during the Holocene (part 2) -Fault activity of the northern part and segmentation model—, CRIEPI report, U95060, $42 \mathrm{p}, 1996$.

Tsukuda, E., Y. Awata, H. Yamazaki, Y. Sugiyama, K. Shimokawa, and K. Mizuno, Explanatory text of the strip map of the Atera Fault system, scale 1:25,000, Tectonic map series (7), 39 pp, Geol. Surv. Jpn., 1993 (in Japanese with English abstract).

Villaescusa, E., M. Seto, and G. Baird, Stress measurements from oriented core, Int. J. Rock Mech. Min. Sci., 39, 603-615, 2002.

Yamamoto, K., A theory of rock core-based methods for in-situ stress measurement, Earth Planets Space, 61, 1143-1161, 2009.

Yamamoto, K., Y. Kuwahara, N. Kato, and T. Hirasawa, Deformation rate analysis: A new method for in situ stress estimation from inelastic deformation of rock samples under uniaxial compressions, Tohoku Geophys. J. (Sci. Rep. Tohoku Univ., Ser. 5), 33, 127-147, 1990.

Yamamoto, K., H. Yamamoto, N. Kato, and T. Hirasawa, Deformation rate analysis for in situ stress estimation, AE/MS activity, in Geol. Struct. and Mat., edited by H. R. Hardy Jr., 243-255, Trans. Tech. Pub., 1993.

Yamashita, F., K. Mizoguchi, E. Fukuyama, and K. Omura, Reexamination of the present stress state of the Atera fault system, central Japan, based on the calibrated crustal stress data of hydraulic fracturing tests obtained by measuring the tensile strength of rocks, J. Geophys. Res., 2009 (in press).

Y. Yabe (e-mail: yabe@aob.gp.tohoku.ac.jp), K. Yamamoto, N. Sato, and K. Omura 